\title{
3 Research Square

\section{Narrowing but Persisting Gender Pay Gap among Employees of the US Department of Health and Human Services during 2010-2018}

Zhuo (Adam) Chen ( $\square$ zchen1@uga.edu )

University of Georgia College of Public Health https://orcid.org/0000-0002-5351-3489

Yihong Zhang

University of Nottingham - Ningbo China

Huabin Luo

East Carolina University Brody School of Medicine

Donglan Zhang

University of Georgia College of Public Health

Janani Rajbhandari-Thapa

University of Georgia College of Public Health

Yuheng Wang

Charles River Associates

\section{Ruoxi Wang}

Huazhong University of Science and Technology

Grace Bagwell-Adams

University of Georgia College of Public Health

\section{Research}

Keywords: Health workforce, US Department of Health and Human Services, gender pay gap, occupational segregation

Posted Date: February 10th, 2021

DOl: https://doi.org/10.21203/rs.3.rs-168996/v1

License: (c) (i) This work is licensed under a Creative Commons Attribution 4.0 International License.

Read Full License 


\section{Abstract}

Background. The gender pay gap in the United States (US) has narrowed over the last several decades, with the female/male earnings ratio in the US increased from about $60 \%$ before the 1980 s to about $79 \%$ by 2014 . However, the gender pay gap among the healthcare workforce persists. The objective of this study is to estimate the gender pay gap in the US federal health workforce during 2010-2018.

Methods. We used an administrative dataset including annual pay rates and job characteristics of employees of the US Department of Health and Human Services. Employees' gender was classified based on first names. Regression analyses were used to estimate the gender pay gap using the predicted gender.

Results. Women employees of the DHHS earn about 13\% less than men in 2010, and $9.2 \%$ less in 2018 . Occupation, pay plan, and location explain more than half of the gender pay gap. Controlling job grade further reduces the gap. The unexplained portion of the gender pay gap in 2018 may fall between $1.0 \%$ and $3.5 \%$. Women have a small advantage in terms of pay increase over the study period.

Conclusions. While the gender pay gap has narrowed within the last two decades, the pay gap between men and women in the federal health workforce persists and warrants continuing attention and research. Continued efforts should be implemented to reduce the gender pay gap among the health workforce.

\section{Background}

The United States (US) has seen a narrowing gender pay gap over the last two decades.[1] Although further efforts to address gender-based inequities in pay have been stalled, Congress restored the requirement for equal pay for equal work by passing the Lily Ledbetter Fair Pay Act in 2009.[2] The female/male earnings ratio in the US has increased from about $60 \%$ before the 1980 s to about $79 \%$ by 2014.[1] The gender pay gap among the healthcare workforce continues to exist and is considered a social determinant of health.[3] For instance, male nurses earned $27.9 \%$ more than female nurses in 2013 in the US although the gap reduced to about $9.8 \%$ once work hours were controlled.[4] A gender wage gap varied across occupations among a sample of 10,066 Australian full-time employees within the health section during 2005-2006.[5]

Examining the gender pay gap in the public sector is of particular interest because public entities often have a mandate of equal pay for equal work. In the US, the gender pay gap persists among public employees at various levels. Chen and Crown finds a gender pay gap of $11 \%$ among regular, tenure-track faculty in a public university in 2016, i.e., women earn 89 cents for every dollar paid to men.[6] Another study finds that men earned $29.6 \%$ more than women among US primary and secondary school teachers although the adjusted gap reduced to 14.6\%.[4] The US federal government, the largest public employer in the country, has seen the gender pay gap among its workforce declined from $28 \%$ in 1988 to $19 \%$ in 1998 , and to $11 \%$ in 2008.[7] An agency-specific study produces similar findings, with a narrowed gap from 22\%-31\% in 1994 to 10\%-27\% in 2008.[8] The US Government Accountability Office (GAO) reported an 11 
cents difference in pay between men and women of the federal workforce in 2007, among which 7 cents cannot be explained with occupation or education.[9] As the acquisition of personnel data for research purposes often involve a time lag, earlier studies, including a paper published in 2019, have only been able to examine the federal workforce during 1988-2008.[7, 8, 10]

Several strands of literature exist in explaining the gender pay gap. The economic literature decomposes the gender pay gap into contributions of human capital, occupational segregation, and an unexplained portion that often considered as evidence of discrimination.[8-10] Other studies have hypothesized that work hours and wage-setting institutions contributed to the gender pay gap.[11-13] Psychological attitudes towards competition might have accounted for some but a limited portion of the gender pay gap.[14] Childbearing and family roles may have also contributed to the gender difference in career advancement and thus pay.[15] However, the GAO study suggested that unpaid leave and break in service could explain less than one percent of the gender pay gap.[9]

The US Department of Health and Human Services (DHHS) is a cabinet-level agency of the federal government with more than 80,000 employees.[16] Most of the DHHS employees are skilled labor with special knowledge on health services, medicine, and other allied health or supporting disciplines, representing a significant portion of the public health workforce. In addition, the DHHS is considered as a gender-neutral agency versus masculine agencies such as the Department of Homeland Security.[8] Earlier studies have taken an agency-specific approach to separate the impact of organizational cultures and social norms on the gender pay gap. $[8,10]$ However, none of the prior studies has focused on the federal health workforce, and there is a lack of updated analyses on the gender pay gap since 2008 .

This paper intends to examine and explain the gender pay gap among the employees of the US DHHS during 2010-2018. A key innovation is our use of an online federal employee salary database and the recently released Social Security Administration (SSA) database of first names of newborns. The online portal obtained the salary information of federal employees through Freedom of Information Act (FOIA) requests.[17] We use the SSA online database, supplemented with an online state employee database to predict the gender information. Our results provide a timely update on the gender pay gap within the US federal health workforce.

\section{Method}

\section{Data}

The primary data of this study were scraped from FedsDataCenter.com using Python.[17] FedSmith Inc. acquired the salary data of federal employees through FOIA requests and provided the information for free through FedsDataCenter.com. We extracted information on the name and salaries of employees of the US DHHS during 2010-2018 except for 2014. The data during 2010-2013 were scrapped for an earlier project. The data for 2014 were not available when we started scraping again in 2019. Additional data fields included the location where the employee is stationed, job title, pay plan, and pay grade. 
The key dependent variable was the salary, the annual pay rate documented in the employee's human resource record. The pay rate might differ from the employee's exact pay during the year if the employee had any personnel changes in the system. However, it reflected employee's base pay rate during the fiscal year.

Location was an important factor in determining federal employees' salaries. As a measure to adjust for the cost of living, federal salaries varied across locations (domestic and foreign) with a multiplicative factor, which was authorized under Title 5 US Code Sect. 5304 and applicable to most employees of GS and several other pay plans.[18] Pay plans were a set of tables or arrays of pay rates "prescribed by law or other authoritative source that establishes the basic pay rates for certain employees."[19] The most common federal pay plan was the GS plan.

Grade or pay grade was the 15 levels on the bureaucratic ladder in the GS plan, ranging from GS-1 to GS15.[18] Higher pay grades often require advanced degrees and thus higher pay rates. GS-14 and GS-15 typically involve supervisory responsibilities. For each grade level, there were ten "steps" through which the employees may advance by accumulating sufficient length of service or by merit.

Job titles were descriptive texts provided by agency human resource departments. The texts were an approximation of occupations although the accuracy of the texts relies on the practice of the specific human resource specialist. Multiple variations or abbreviations of a job title might exist. These issues could lead to over-stratified categories but would not affect the main results of our analysis.

Names of the DHHS employees were also available as part of the FOIA requests.[20]

\section{Predicting Gender Based on First Names}

Predicting gender base on first names had been increasingly applied in research using names scraped online.[21,22] To determine the gender of the employees, we used the SSA database of baby names with at least five uses in a year from 1940-2000. We ascertained an HHS employee's gender by assigning the gender that appeared in the database at least $95 \%$ of the time.

The SSA database contained the first names of those who were born in the US thus might not capture the first names of foreign-born employees. To augment the SSA database, we used a database from the state of lowa,[20] which publishes salary information of state employees, in addition to their full name and gender. The lowa database helped us to determine the gender of some employees whose first names had not appeared in the SSA records, including hyphened compound first names and first names that came from foreign languages.

By using the SSA records and the lowa database, we were able to assign genders to 6,890 female first names and 3,542 male first names, for 111,320 unique names (first name and family name) and 518,575 records over the eight years.

\section{Analytic Approaches}


We regressed the logarithm of the annual pay on a set of control variables and the assigned gender indicator for each year. The first set of control variables included the fixed effects of location. The logarithm of salary allowed the multiplicative nature of the locality adjustment. The second set included fixed effects of job title and pay plan to control for the effects of occupation and managerial responsibilities. The third set of control variables added the fixed effects of job grade, which approximates the impact of promotion and managerial responsibilities.

Utilizing the longitudinal nature of the data, we examined the gender difference in salary increase over the study period. However, the DHHS employee records had multiple namesakes in a year. Because we could not differentiate an employee from their namesakes over time, we removed any names that appeared more than once in a given year. We constructed a panel over time but opted not to use the employee fixed effects because the fixed effects will absorb the gender difference. The large number of fixed effects also exceeds our available computation capacity. With the remaining sample of unique names, we subtracted the logarithm of pay for an employee in the previous year from that in the current year and used the difference as a dependent variable. We regressed the resulted difference over the three set of control variables.

\section{Ethics Review}

Our research is a secondary analysis based on public records thus IRB review is not required.

\section{Results}

We have identified the gender of most employees during 2010-2018 (Table 1), resulting from a low of 51,943 in 2015 to a high of 74,511 employees in 2012 used in the analysis. A sharp drop in the number of DHHS employees shown in the FedsDataCenter.com data occurred in 2015. 
Table 1

Identifying the Gender of DHHS Employees Based on First Names

\begin{tabular}{|c|c|c|c|c|c|c|c|}
\hline \multirow[t]{2}{*}{ Year } & \multirow{2}{*}{$\begin{array}{l}\text { Total } \\
\text { number of } \\
\text { DHHS } \\
\text { employees }\end{array}$} & \multirow{2}{*}{$\begin{array}{l}\% \text { of DHHS } \\
\text { employees } \\
\text { whose } \\
\text { gender is } \\
\text { not } \\
\text { identified }\end{array}$} & \multicolumn{2}{|c|}{$\begin{array}{l}\text { Among those whose } \\
\text { gender is identified }\end{array}$} & \multicolumn{2}{|c|}{ Average Pay } & \multirow[t]{2}{*}{$\begin{array}{l}\text { Female/Mal€ } \\
\text { Pay ratio }\end{array}$} \\
\hline & & & $\begin{array}{l}\% \text { of GS } \\
\text { employees }\end{array}$ & $\begin{array}{l}\% \\
\text { Woman }\end{array}$ & Men & Women & \\
\hline 2010 & 81,111 & $11.5 \%$ & $82.2 \%$ & $58.9 \%$ & $\$ 94,675$ & $\$ 82,370$ & $87.0 \%$ \\
\hline 2011 & 83,277 & $11.8 \%$ & $82.1 \%$ & $58.8 \%$ & $\$ 94,845$ & $\$ 83,653$ & $88.2 \%$ \\
\hline 2012 & 84,636 & $12.0 \%$ & $82.2 \%$ & $58.8 \%$ & $\$ 95,480$ & $\$ 84,693$ & $88.7 \%$ \\
\hline 2013 & 84,595 & $12.2 \%$ & $82.9 \%$ & $58.8 \%$ & $\$ 96,063$ & $\$ 86,090$ & $89.6 \%$ \\
\hline 2015 & 60,243 & $13.8 \%$ & $82.7 \%$ & $59.2 \%$ & $\$ 100,941$ & $\$ 90,592$ & $89.7 \%$ \\
\hline 2016 & 61,399 & $14.6 \%$ & $83.8 \%$ & $59.0 \%$ & $\$ 101,695$ & $\$ 91,689$ & $90.2 \%$ \\
\hline 2017 & 70,831 & $15.0 \%$ & $83.7 \%$ & $59.4 \%$ & $\$ 105,582$ & $\$ 95,766$ & $90.7 \%$ \\
\hline 2018 & 73,858 & $15.4 \%$ & $83.5 \%$ & $59.6 \%$ & $\$ 109,542$ & $\$ 99,515$ & $90.8 \%$ \\
\hline
\end{tabular}

GS employees comprise about $82-83 \%$ of the DHHS employee. The percent of women among DHHS employees has been stable at around 59\% (Table 1), while the percentage is higher at roughly $63 \%$ among GS employees.

Comparing the average pay reveals a narrowing but persistent gender pay gap, starting at about $\$ 12,305$ (13\%) in 2010 to roughly $\$ 10,027$ (9.2\%) in 2018 (calculations based on Table 1). Controlling for location has a marginal reduction of the gap in terms of the percentage difference (Table 2). For example, the regression produces a negative coefficient of -0.131 for being female in 2010, suggesting women earn $13.1 \%$ less than men in 2010. Similarly, women earn 8.3\% less than men in 2018. 
Table 2

Gender Pay Gap by Year among US DHHS Employees during 2010-2018

\section{Dep. Var:} In(salary)

\section{$\begin{array}{llllllll}2010 & 2011 & 2012 & 2013 & 2015 & 2016 & 2017 & 2018\end{array}$}

Panel 1: Controlling location

$\begin{array}{lllllllll}\text { Woman } & -0.131^{*} & -0.118^{*} & -0.111^{*} & -0.101^{*} & -0.094^{*} & -0.086^{*} & -0.084^{*} & -0.083^{*} \\ & (0.003) & (0.003) & (0.003) & (0.003) & (0.004) & (0.004) & (0.003) & (0.003) \\ R^{2} & 0.323 & 0.336 & 0.338 & 0.348 & 0.346 & 0.351 & 0.343 & 0.346\end{array}$

Panel 2: Controlling location, occupation, and pay plan

$\begin{array}{lllllllll}\text { Woman } & -0.053^{*} & -0.049 * & -0.050^{*} & -0.046^{*} & -0.044^{*} & -0.035^{*} & -0.028^{*} & -0.035^{*} \\ & (0.002) & (0.002) & (0.002) & (0.002) & (0.003) & (0.002) & (0.003) & (0.002) \\ R^{2} & 0.736 & 0.734 & 0.740 & 0.739 & 0.722 & 0.724 & 0.664 & 0.736\end{array}$

Panel 3: Controlling location, occupation, pay plan, and grade

$\begin{array}{lllllllll}\text { Woman } & -0.018^{*} & -0.019^{*} & -0.020^{*} & -0.017^{*} & -0.016^{*} & -0.010^{*} & -0.008^{*} & -0.010^{*} \\ & (0.001) & (0.001) & (0.001) & (0.001) & (0.001) & (0.001) & (0.002) & (0.001) \\ R^{2} & 0.897 & 0.889 & 0.887 & 0.892 & 0.886 & 0.907 & 0.862 & 0.903\end{array}$

Note: DHHS: US Department of Health and Human Services; Standard errors in parentheses; * $\mathrm{p}<$ 0.0001

After controlling the fixed effects of job title and pay plan in addition to location, the gender pay gap narrowed substantially. The remaining unexplained gender pay gap is $5.3 \%$ in 2010 and $3.5 \%$ in 2018 , suggesting that women earn $5.3 \%$ less than men in 2010 and $3.5 \%$ less in 2018, accounting for the location factors, occupation selection (or occupational segregation), and selection into administrative duties. The last set of control variables added an additional set of the fixed effects of grade, resulting in the smallest unexplained gap of $1.8 \%$ in 2010 and $1.0 \%$ in 2018 (Table 2).

The regression on the rate of pay increase suggested women do have a slightly higher rate $(0.82$ percentage point) of pay increases than men controlling only location (Table 3 ). However, once occupation and pay plans are controlled, the advantage narrowed down to 0.39 percentage points. If the grade level is also controlled, the difference is even smaller - suggesting that women have a rate of pay increase that is 0.24 percentage point higher than men. Similar results are observed for the sample of GS employees. 
Table 3

Gender Gap in Pay Growth among US DHHS Employees during 2010-2018
Dep var: $\ln \left(\right.$ salary $_{\mathrm{t}} /$ salary $\left._{\mathrm{t}-1}\right)$
(1)
(2)
(3)

All HHS employees who does not have namesakes in the year

\begin{tabular}{llll} 
Woman & $0.0082^{*}$ & $0.0039^{\star}$ & $0.0024^{\star}$ \\
\hline$R^{2}$ & $(0.0006)$ & $(0.0006)$ & $(0.0006)$ \\
\hline
\end{tabular}

HHS GS employees who does not have namesakes in the year

\begin{tabular}{llll} 
Woman & $0.0064^{*}$ & $0.0027^{*}$ & 0.0010 \\
\hline$R^{2}$ & $(0.0006)$ & $(0.0006)$ & $(0.0006)$ \\
\hline & 0.072 & 0.108 & 0.117
\end{tabular}

Note: DHHS: US Department of Health and Human Services; Standard errors in parentheses; * $\mathrm{p}<$ 0.0001; Model 1 controls for the fixed effects of location; Model 2 controls for the fixed effects of location, job title, and pay plan; Model 3 controls for the fixed effects of location, job title, pay plan, and grade.

\section{Discussions}

This study use an administrative dataset of annual pay rates of US DHHS employees, coupled with use of the SSA first name database and a database of the State of lowa employee salaries, to assess the gender pay gap among the federal health workforce. We find a narrowing but persisting gender pay gap, after controlling for location, job title, pay plan, and job grade.

The data from FedsDataCenter.com provide a close approximation of the DHHS administrative record. Our estimated proportion of women in the DHHS workforce is slightly less than $60 \%$, which is consistent with the proportion reported in earlier studies using administrative data in 2006[15] or employee survey data in 2004.[23] This may indicate a willingness of women to self-select into health-related fields.[24]

The estimated gender pay gap (a female-to-male pay ratio of $91.8 \%$ in 2018) from this study is similar to what is published on Fedscope.com, which shows an average pay of $\$ 98,409$ for women and $\$ 106,723$ for men among DHHS employees in 2018, resulting in a female-to-male pay ratio of $92 \%$.[25] The estimated trend of a narrowing gender pay gap observed in this study is consistent with earlier research examining different components of the federal workforce [7-9] and the trend across the high-income countries.[26] Fig. 1 illustrates the female-to-male pay ratio over time estimated from this study and two earlier publications. Even though they have examined different parts of the federal government, they reveal a consistent trend. In comparison, a recent analysis found that the percent of female chief executive officers of the UK National Health Services foundation trusts has increased from $37 \%$ in 
$2012 / 13$ to $47 \%$ in $2017 / 18$, and the gender pay gap among them has diminished over the same time period.[26]

The narrowing gender pay gap can be explained by the increase in education and experience as well as an increased entry of women into occupations that had been dominated by men. $[1,7-9,15,27]$ The GAO reported has identified a contributing factor that may be both encouraging and concerning - the clerical positions that were dominated by women have been diminishing in the federal government.[9] The diminishing clerical positions is encouraging because it may indicate that technological and social changes have enabled and empowered women to enter a broad array of fields. However, the federal government's use of contractors may lead to more women being hired as contractors, whose pay will not appear in the database thus unaccounted for in the calculation of gender pay gaps.[28]

The GAO report, though acknowledged the narrowing gender pay gap among the federal workforce, has also pointed to an important concern - the portion of the gender pay gap that cannot be explained by occupation, experience, and education increased from 2 cents in 1988 to 7 cents in 2007. Our study suggests that occupation and pay plan explained about 8 cents (the difference between -0.053 and 0.131 ) of the gender pay gap in 2010 , and 5 cents in 2018 . Including the pay grade explains an additional 2.5 cents in 2010 and 2018. However, because pay grade is a proxy of promotion, it may have components that can be explained by education, years of government service, as well as an unexplained portion. Similar to what has been observed among the employees of the Mexican National Insitutes of Health,[24] the distribution of women employees across different grades of the GS has been uneven, with the smallest portion of women reaching the highest grade, GS-15, and higher percentages of women employees at lower grade levels (e.g., GS-13). Given a grade level, women earn slightly more than men at lower grade levels, but the advantage starts to disappear at grade level 13 (Appendix Table 1). Hence, the unexplained portion of the gender pay gap may lie within the interval determined by models 2 and 3, i.e., between 1.8 and 5.3 cents in 2010 and between 1.0 and 3.5 cents in 2018 .

Competing theories exist in explaining the unexplained portion of the gender pay gap, e.g., childcare and wage structure,[1, 11, 12] gender difference in psychological attitude,[14] upaid overtime,[5] and the lack of role models.[15] Employee viewpoint survey or focus group interviews may help to pinpoint the exact causes of the remaining gender pay gaps.

Policies and interventions to reduce the gender pay gap include a one-time pay raise for women employees as the University of Essex did,[29] and the Denmark and UK mandates for institutions to publish gender pay gaps. Such mandates have been shown to have narrowed the gender pay gap in the UK and Denmark.[30-32]

\section{Limitations}

This study has several limitations. First, FOIA requests are handled within a set timeframe, often at the price of quality control. Agency might also have different policies as to what information to be withheld over time. We have seen the variation in our sample size, which dipped after 2014 . However, if the quality 
control or information withheld does not vary systematically across the gender groups, our results will not be critically impacted, which seems to be the case as we have seen the consistent trend in the estimated gender pay gap. Second, we have more than $10 \%$ of the first names that cannot be assigned a gender. Some of the names are gender-neutral names, such as "Drew" or "Robin", that neither gender had been used at least $95 \%$ of the time during 1940-2000. Though in general, they are more likely to be female, thus our estimated gender pay gap may bias slightly upward as those who cannot be assigned a gender have a higher average salary. Some of the other names that cannot be assigned gender are from foreign languages, which is difficult to determine the direction of the biases from dropping those names. However, the resulted bias may be negligible because the Fedscopes.com data provide strong support for our results. Third, the job titles provided through FOIA requests are often unstructured texts with many different forms of abbreviations and variations. This leads to issues where multiple fixed effects are estimated for the same occupation. However, the additional degree of freedom is trivial, given the large sample size of this study. Fourth, we do not have information on experience, education, and race and ethnicity. Meanwhile, pay grade may capture some of the differences in experience and education because specific requirements on education and experience exist for progressing to a particular pay grade.

\section{Conclusions}

Our results have important implications. The gender pay gap is a social determinant of health that affects the outcomes of the public health system. A narrowing gender pay gap, from $13 \%$ in 2010 to $9.2 \%$ in 2018 at DHHS, the nation's premier health agency, is encouraging news for practitioners. Identifying the unexplained portion of the gap will pave the way to reducing and ultimately eliminating the gender pay gap.

In line with the mandate to publish gender pay gap in the UK, our research calls for added data transparency. While the federal initiative to publish data through data.gov is commendable, making the data available to the research community at the same speed as responding to the FOIA requests would improve the efficiency of research and evaluation of gender pay equity among the federal workforce.

\section{Declarations}

\section{Ethics approval and consent to participate}

Our research is a secondary analysis based on public records thus IRB review is not required.

\section{Consent for publication}

Not Applicable 


\section{Availability of data and materials}

The datasets used and/or analysed during the current study are available from the corresponding author on reasonable request.

\section{Competing interests}

The authors declare no competing interests.

\section{Funding}

Dr. Chen acknowledges funding from the 2021 Teaming for Interdisciplinary Research (TIR) Pre-Seed Program, the Office of Research, University of Georgia.

\section{Authors' contributions}

Z. Chen and H. Luo conceived the study. Z. Chen provided supervision and coordination. Y. Wang collected the data via web scraping. Y. Zhang applied the machine learning algorithm for matching gender with first names. Z. Chen and Y. Zhang completed the analyses. Z. Chen led the writing of the first draft with significant contributions from H. Luo, D. Zhang, and R. Wang. D. Zhang and R. Wang assisted in data analysis. J. Thapa and G. Bagwell-Adams contributed to the critical review and editing of the manuscript, in particular the interpretation of the results. All authors have reviewed and approved the final version of the manuscript.

\section{Acknowledgements}

None.

\section{References}

1. Blau FD, Kahn LM. The Gender Wage Gap: Extent, Trends, and Explanations. Journal of Economic Literature. 2017;55(3):789-865.

2. Hamidullah MF, Riccucci NM, Lee IP. Citizens' perceptions of closing the gender pay gap: an experimental study. Public Management Review 2020.

3. Treadwell H. Wages and Women in Health Care: The Race and Gender Gap. American journal of public health 2019;109(2).

4. Wilson BL, Butler MJ, Butler RJ, Johnson WG. Nursing Gender Pay Differentials in the New Millennium. J Nurs Scholarsh. 2018;50:102-8. 
5. Vecchio N, Scuffham PA, Hilton MF, Whiteford HA. Differences in wage rates for males and females in the health sector: a consideration of unpaid overtime to decompose the gender wage gap. Human Resources for Health. 2013;11(1):9.

6. Chen JJ, Crown D. The Gender Pay Gap in Academia: Evidence from the Ohio State University. Am J Agr Econ. 2020;101(5):1337-52.

7. Bolitzer B, Godtland EM. Understanding the Gender-Pay Gap in the Federal Workforce Over the Past 20 Years:. American Review of Public Administration. 2012;42(6):730-46.

8. Smith-Doerr L, Fitzpatrick D, Alegria S, Tomaskovic-Devey D, Fealing KH. Gender Pay Gaps in U.S. Federal Science Agencies: An Organizational Approach1. Am J Sociol. 2019;125(2):534-76.

9. Office USGA. Women's Pay: Gender Pay Gap in the Federal Workforce Narrows as Differences in Occupation, Education, and Experience Diminish. In: GAO, ed.: @USGAO; 2009.

10. Choi S. Pay Equity in Government: Analyzing Determinants of Gender Pay Disparity in the U.S. Federal Government:. Administration Society. 2018;50(3):376-1.

11. Arulampalam W, Booth A, Bryan ML. Is There a Glass Ceiling over Europe? Exploring the Gender Pay Gap across the Wage Distribution:. ILR Review. 2007;60(2):163-86.

12. Blau FD, Kahn LM. Analyzing the gender pay gap. The Quarterly Review of Economics Finance. 1999;39(5):625-46.

13. Lo Sasso A, Richards M, Chou C, Gerber S. The $\$ 16,819$ pay gap for newly trained physicians: the unexplained trend of men earning more than women. Health Aff. 2011;30(2):193-201.

14. Manning A, Saidi F. Understanding the Gender Pay Gap: What's Competition Got to Do with it?:. Ind Labor Relat Rev. 2010;63(4):681-98.

15. Chen Z, Roy K, Crawford C. Examining the Role of Gender in Career Advancement at the Centers for Disease Control and Prevention. American Journal of Public Health 2010:426-34.

16. USDHHS. About. HHS | HHS.gov, https://www.hhs.gov/about/index.html; [accessed August 23, 2020.2020].

17. FedsDataCenter.com. Search Federal Employee Salaries, https://www.fedsdatacenter.com/federalpay-rates/; [accessed August 23, 2020.2020].

18. OPM.GOV. Administering Locality Rates, https://www.opm.gov/policy-data-oversight/pay-leave/payadministration/fact-sheets/administering-locality-rates/; 2020 [accessed August 23, 2020.2020].

19. Pay OPMGOV, Plans. https://www.opm.gov/policy-data-oversight/pay-leave/payadministration/fact-sheets/pay-plans/; 2020 [accessed Au.2020].

20. DesMoniesRegister D. State of lowa employee salaries | DesMoinesRegister.com, https://db.desmoinesregister.com/state-salaries-for-iowa; 2020 [accessed August 23, 2020.2020].

21. Wais K. Gender Prediction Methods Based on First Names with genderizeR. The R Journal. 2016;8(1):17-37.

22. West J, Jacquet J, King M, Correll S, Bergstrom C. The Role of Gender in Scholarly Authorship. 2013;8(7):e66212. 
23. Leider J, Harper E, Shon J, Sellers K, Castrucci B. Job Satisfaction and Expected Turnover Among Federal, State, and Local Public Health Practitioners. American journal of public health. 2016;106(10):1782-8.

24. Rivera-Romano LS, Fresno C, Hernández-Lemus E, Martínez-García M, Vallejo M. Gender imbalance in executive management positions at the Mexican National Institutes of Health. Human Resources for Health 2020;18(1).

25. OPM.GOV. Federal Workforce Data: FedScope, https://www.fedscope.opm.gov/; [accessed August 30.2020].

26. Ellwood S, Garcia-Lacalle J, Royo S. The shattered glass ceiling and a narrowing gender pay gap in NHS foundation trusts: gender and salaries of chief executives. Public Money Management. 2020;40(1):31-41.

27. Hunt VH, Rucker L, Kerr B. You've Come a Long Way, Baby, but You Still Have a Long Way to Go: Gender-Based Pay Inequality in U.S. State Bureaucracies, 1995-2015.. Public Personnel Management 2019.

28. Fernandez S, Malatesta D, Smith CR. Race, Gender, and Government Contracting: Different Explanations or New Prospects for Theory? Public Adm Rev. 2012;73(1):109-20.

29. Frank J. The Persistence of the Gender Pay Gap in British Universities. Fiscal Studies 2020.

30. Leaker D. The gender pay gap in the UK. Economic Labour Market Review. 2008;2(4):19-24.

31. Deakin S, Fraser Butlin S, McLaughlin C, Polanska A. Are litigation and collective bargaining complements or substitutes for achieving gender equality? A study of the British Equal Pay Act. Camb J Econ. 2015;39(2):381-403.

32. Bennedsen M, Simintzi E, Tsoutsoura M, Wolfenzon D. Do Firms Respond to Gender Pay Gap Transparency? NBER Working Papers 2019(\#25435).

\section{Figures}


1

0.95

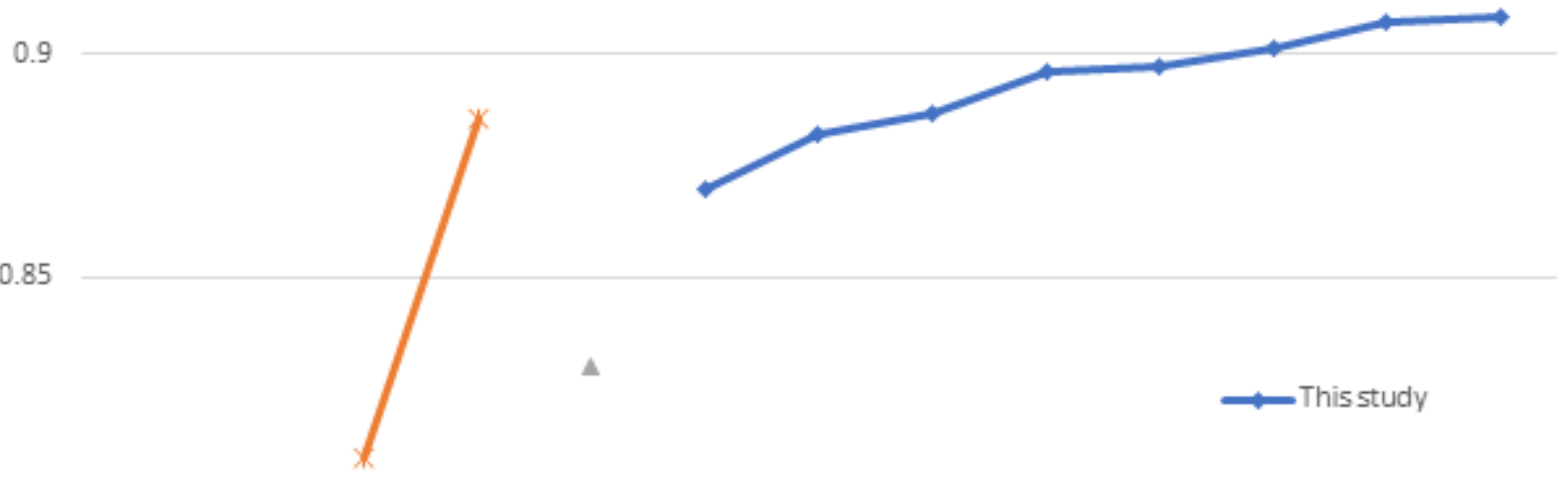

0.8

- Bolitzer \& Godtland

$\Delta$

-Smith-Doerr et al.

0.75

*

0.7

0.65

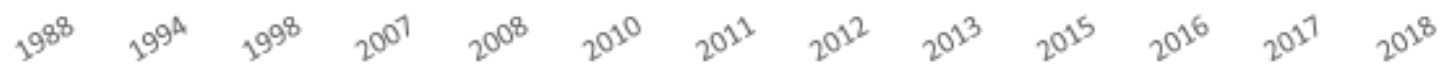

Figure 1

Estimated Female to Male Pay Ratio among the US Federal workforce

\section{Supplementary Files}

This is a list of supplementary files associated with this preprint. Click to download.

- AppendixTable1.docx 